\title{
Lesions Limited to the Human Thalamic Principal Somatosensory Nucleus (Ventral Caudal) Are Associated with Loss of Cold Sensations and Central Pain
}

\author{
Jong H. Kim, ${ }^{1}$ Joel D. Greenspan, ${ }^{2}$ Robert C. Coghill, ${ }^{3}$ Shinji Ohara, ${ }^{4}$ and Frederick A. Lenz ${ }^{1}$ \\ ${ }^{1}$ Department of Neurosurgery, Johns Hopkins Hospital, Baltimore, Maryland 21287-7713, ${ }^{2}$ Department of Biomedical Sciences, University of Maryland \\ Dental School and University of Maryland Program in Neuroscience, Baltimore, Maryland 21201, ${ }^{3}$ Department of Neurobiology and Anatomy, Wake Forest \\ University School of Medicine, Winston-Salem, North Carolina 27157, and ${ }^{4}$ Department of Neurosurgery, Kyoto Kizugawa Hospital, Kyoto 610-0101, Japan
}

\begin{abstract}
Central pain is neuropathic pain resulting from a lesion of the CNS, such as a stroke [poststroke central pain (CPSP)]. Lesions involving the posterior thalamus lead to reduction or loss of sensation and to CPSP, although the responsible nuclei have not been identified. We now examine the hypotheses that thalamic lesions must extend posterior to the ventral caudal nucleus (Vc) and include ventral medial posterior nucleus (VMpo), to result in loss of cold sensibility and CPSP. Patients with small thalamic strokes associated with CPSP were evaluated by atlas-based mapping of magnetic resonance imaging scans, and by somatosensory testing. All lesions involved posterior Vc; two lesions also involved nuclei posterior to Vc, but not VMpo. All patients tested had alterations of cold pain sensation and tactile sensation, as measured by von Frey hairs. Three patients had altered cool sensation, and the patient with the least involvement of Vc had normal cool thresholds, suggesting that a critical volume of Vc must be involved before cool sensation is impaired. Perception of warm was impaired only in lesions involving nuclei posterior to Vc. Heat pain perception was never affected. In a subject with cold allodynia, a single-subject protocol PET study measured the responses to immersion of either hand in a $20^{\circ} \mathrm{C}$ waterbath. The scan during stimulation of the affected hand was characterized by intense activation of contralateral sensorimotor cortex. Therefore, there are modality-specific subnuclear structures in the posterior thalamus, but lesions of Vc not involving VMpo are sufficient to impair cold sensibility and to produce CPSP.
\end{abstract}

Key words: pain; cold; ventral posterior thalamus; stroke; human; somatosensory

\section{Introduction}

Patients with central pain commonly have lesions of the spinothalamic tract (STT) or the thalamocortical structures to which it projects (Cassinari and Pagni, 1969). Central pain is often described in terms both of thermal stimuli, such as burning, and of pain evoked by cold or tactile stimuli that are not normally painful (allodynia) (Leijon et al., 1989; Vestergaard et al., 1995). On quantitative somatic sensory testing, patients with CPSP exhibit diminished thermal and pain sensations, modalities that are largely mediated through the STT (Boivie et al., 1989; Andersen et al., 1995; Greenspan et al., 2004). These observations suggest that a lesion of the structures that receive input from the STT are associated with impairment of thermal and pain sensations, and with CPSP (Jones, 1985; Willis, 1985; Casey, 1991; Steriade et al., 1997).

Received Feb. 16, 2007; revised March 29, 2007; accepted April 1, 2007.

This work was supported by National Institutes of Health-National Institute of Neurological Disorders and Stroke Grants NS38493 and NS40059 (F.A.L.), NS-39337 (J.D.G.), and NS 39426 (R.C.C.). We thank L. H. Rowland, C. Cordes, and E. M. Rosier for excellent technical assistance, I. Gilron for the medical examination before the PET scan, and M. ladarola for his support of these studies.

Correspondence should be addressed to Frederick A. Lenz, Department of Neurosurgery, Johns Hopkins Hospital, Meyer Building 8-181, 600 North Wolfe Street, Baltimore, MD 21287-7713. E-mail: flenz1@jhmi.edu.

D01:10.1523/JNEUROSCI.0716-07.2007

Copyright $\odot 2007$ Society for Neuroscience $\quad$ 0270-6474/07/274995-11\$15.00/0
The recent version of the disinhibition hypothesis proposes that central pain results from a lesion producing an imbalance between two STT pathways arising from lamina I of the spinal dorsal horn. In this hypothesis, the lateral STT includes a proposed cold-signaling pathway that projects to the insula through ventral medial posterior nucleus (VMpo) (Craig et al., 1996). In patients with CPSP, it is proposed that a lesion of this pathway disinhibits a proposed medial STT pain-signaling pathway projecting to anterior cingulate cortex (ACC) via the medial dorsal nucleus (Craig, 2000) (cf. Vogt and Sikes, 2000). According to this hypothesis, lesions of VMpo lead to cold hypoesthesia and to the disinhibition of the ACC, which results in the burning pain of CPSP. Therefore, the precise location of small thalamic lesions associated with thermal and pain sensory loss is a critical test of structures mediating these sensations and CPSP.

Previous studies have used routine interpretation of structural imaging studies to identify lesions of the posterior thalamus leading to CPSP. Some studies have identified lesions that may be limited to ventral caudal (Vc) (Hirai and Jones, 1989; Leijon et al., 1989; Vestergaard et al., 1995; Bowsher et al., 1998). One case report used atlas-based mapping of magnetic resonance images to locate a stroke involving a large part of $\mathrm{Vc}$ and sparing $\mathrm{VMpo}$ (Montes et al., 2005). Formal somatic sensory testing was not consistently performed in these studies. 
Table 1. Clinical features of the patients in this series

\begin{tabular}{|c|c|c|c|c|c|c|c|c|c|c|}
\hline $\begin{array}{l}\text { Patient number, } \\
\text { diagnosis, lesion type }\end{array}$ & $\begin{array}{l}\text { Sex/age at } \\
\text { onset/age at } \\
\text { SS test }\end{array}$ & $\begin{array}{l}\text { Stroke side, } \\
\text { nonthalamic } \\
\text { territory }\end{array}$ & Stroke symptoms & $\begin{array}{l}\text { Duration of CPSP or } \\
\text { dysesthesias }\end{array}$ & Latent period & $\begin{array}{l}\text { Intercurrent } \\
\text { illness }\end{array}$ & Neurologic exam & Axial MRI images & Sagittal MRI images & $\begin{array}{l}\text { Maximum dimension } \\
\text { (axial-sagittal) }\end{array}$ \\
\hline 8, CPSP, Vc only & $M / 57 / 59$ & Left, NA & $\begin{array}{l}\text { Transient clumsy hands, } \\
\text { sensory loss, slurred } \\
\text { speech }\end{array}$ & 24 months of CPSP & 18 months & HBP & Rt tremor & $\begin{array}{l}\text { T1 weighted, } 3 \\
\text { mm, }(7, \text { plate } \\
\text { plus } 4 \mathrm{~mm})\end{array}$ & NA & $0.28(7 \mathrm{~mm})-\mathrm{NA}$ \\
\hline 3, CPSP, Vc only & $M / 63 / 66$ & $\begin{array}{l}\text { Right, left medial } \\
\text { occipital plus } \\
\text { temporal } \\
\text { infarct sparing } \\
\text { midbrain and } \\
\text { capsule } \\
\text { (Fig. 2) }\end{array}$ & $\begin{array}{l}\text { Transient numbness, } \\
\text { weakness }\end{array}$ & 33 months of CPSP & 0 & IDDM, CAD & $\begin{array}{l}\text { DTR 2-3/5 on } \\
\text { left, perma- } \\
\text { nent left } \\
\text { homonymous } \\
\text { heminanopsia }\end{array}$ & $\begin{array}{l}\text { T1 weighted, } 1 \\
\text { mm, }(2, \text { plate } \\
\text { plus } 2 \mathrm{~mm})\end{array}$ & $\begin{array}{l}\text { T1 weighted, } 5 \mathrm{~mm}, \\
(142, \text { plate } 46)\end{array}$ & $0.17-2.5$ \\
\hline 18, CPSP, Vc plus & $M / 75 / 78$ & Left, NA & $\begin{array}{l}\text { Transient left-sided } \\
\text { ataxia, numbness }\end{array}$ & 36 months of CPSP & 4 months & HBP & Left-sided ataxia & $\begin{array}{l}\text { T2 weighted } 5 \\
\text { mm, ( } \$ 4126, \\
\text { plate plus } 4 \\
\text { mm) }\end{array}$ & $\begin{array}{l}\text { T1 weighted, } 5 \mathrm{~mm} \text {, } \\
(15, \text { plate } 45)\end{array}$ & $0.37-0.38$ \\
\hline $\begin{array}{l}\text { 13, central dysesthesia } \\
\text { syndrome, Vc plus }\end{array}$ & $M / 69 / 76$ & Right, NA & $\begin{array}{l}\text { Numbness, transient } \\
\text { weakness left arm } \\
\text { and leg }\end{array}$ & $\begin{array}{l}7 \text { years of dysesthe- } \\
\text { sias }\end{array}$ & 2 weeks & HBP & $\begin{array}{l}\text { Minimum dec left } \\
\text { strength, } \\
\text { slowness of } \\
\text { independent } \\
\text { finger move- } \\
\text { ments, Me- } \\
\text { niere's }\end{array}$ & $\begin{array}{l}\text { Flair, } 5 \mathrm{~mm} \text {, } \\
\quad(-11.4 \mathrm{~mm} \text {, } \\
\text { plate plus } 4 \\
\mathrm{~mm})\end{array}$ & $\begin{array}{l}\text { T1 weighted, } 5 \mathrm{~mm} \text {, } \\
(20 \text {, plate } 46)\end{array}$ & $0.26-0.37$ \\
\hline
\end{tabular}

The axial and sagittal magnetic resonance images are described by features including MRI sequence, thickness, and image number (plate from the Shaltenbrand atlas). The maximum dimension of the thalamic lesion is given as a fraction of the ACPC line, unless it can be stated in millimeters (patient 8). CAD, Coronary artery disease; DTR, deep tendon reflexes; HBP, hypertension; IDDM, insulin-dependent diabetes; SS, somatosensory; NA, not available; M, male.

We now test the hypothesis that thalamic lesions leading to loss of cold sensation must include the region posterior to $\mathrm{Vc}$, including VMpo. As a corollary, we test the hypothesis that involvement of this region is a necessary part of lesions leading to CPSP. We have examined somatic sensory loss as a function of nuclear location for the smallest thalamic lesions leading to CPSP. Lesion location was estimated by atlas-based magnetic resonance imaging (MRI) mapping (Hillis et al., 1998; Montes et al., 2005). Studies of sensory impairment or intraoperative thalamic electrophysiology have been described previously in some of these patients (Lenz et al., 1998, 2004; Greenspan et al., 2004; Patel et al., 2006).

\section{Materials and Methods}

All of the methods used in these studies have been described previously (Hillis et al., 1998; Greenspan et al., 2004). The protocol for these studies conformed to the principles stated in the Declaration of Helsinki regarding the use of human subjects and was reviewed and approved annually by the Institutional Review Boards of the Johns Hopkins University, the University of Maryland, Baltimore, and the National Institutes of Health. All subjects were identified by an arbitrary numeric code and signed an informed consent for involvement in this protocol.

\section{Structural imaging studies}

The MRI sequences used for each subject and the Schaltenbrand atlas templates used are given in Table 1. Images were transferred to a workstation running an in-house brain atlas software package. The registration of the magnetic resonance images to the digitized atlas (Schaltenbrand and Bailey, 1959; Talairach and Tournoux, 1988) was performed using local linear registration of the atlas map to the clinical brain image (Nowinski et al., 1996; Hillis et al., 1998). The Schaltenbrand Atlas was chosen because it is the atlas most commonly used for stereotactic surgical procedures and because it has been repeatedly validated against the physiology at surgery (Lenz et al., 1994; Tasker et al., 1997; Ohara and Lenz, 2003) and the histology at autopsy (Gross et al., 2004).

Specific boundaries between the CSF spaces and the diencephalon were aligned with the atlas map by registering different structures including: the walls of the third ventricle, the habenula, anterior and posterior commissures, pulvinar, geniculate bodies, and colliculi. Junctions between gray and white matter structures were also registered including the medial and lateral surfaces of the internal capsule, the claustrum/insular cortex, the striatum, caudate, and pallidum. In the case that not all boundaries or junctions could be simultaneously aligned with the atlas map, we favored the boundaries closest to Vc. After registration, nuclear boundaries from the registered atlas map were used to define the location of the lesion on the patient's magnetic resonance image.

To locate VMpo on these atlas maps, axial sections showing the proposed location of this nucleus were registered with the sections of the Schaltenbrand atlas (Blomqvist et al., 2000). This was also performed by local linear registration based on the borders of the third ventricle, ambient cistern, habenular commissure, posterior commissure, superior colliculus, pulvinar, the posterior border of $\mathrm{Vc}$, and the posteromedial aspect of the internal capsule. VMpo was not seen, and thus is not shown, on some of the Schaltenbrand atlas maps in this figure (Schaltenbrand and Bailey, 1959; Blomqvist et al., 2000).

This technique of determining VMpo was used because the only sections showing human VMpo do not identify standard surgical landmarks used to align the magnetic resonance image, such as the commissures (Blomqvist et al., 2000). In addition, there is uncertainty in the existence and location of VMpo, as determined by STT terminations and staining for calcium-binding proteins (Willis et al., 2001; Craig, 2004; Graziano and Jones, 2004).

\section{Psychophysical tests}

A complete neurologic history and physical examination was performed in each case independently by a neurosurgeon and neurologist, including a detailed clinical assessment of somatic sensory function (Lenz et al., 1993a). We next examined the thresholds for innocuous warm, innocuous cool, heat pain, cold pain, and innocuous tactile sensations, as well as the presence of brushing allodynia. In all sensory testing protocols, subjects were seated comfortably in a dental chair and were unable to see the stimuli.

Warm and cool sensations. Thermal thresholds were derived using a feedback-controlled Peltier stimulator with a $7 \mathrm{~cm}^{2}$ contact area (Mark IX; Forida State University, Tallahassee, FL). A modified Marstock protocol was used to determine thresholds for detection of warm and cool stimuli. The protocol started with the thermal probe (Peltier stimulator) strapped to the test site for $1 \mathrm{~min}$ at an adapting temperature of $33^{\circ} \mathrm{C}$. Thereafter, the temperature was increased (or decreased in separate blocks of trials) at a rate of $1^{\circ} \mathrm{C} / \mathrm{s}$ until the subject pushed the response button to indicate that he/she felt the warm (or the cool) stimulus. At that point, the probe temperature returned to the adapting temperature for an interstimulus interval of $6-10 \mathrm{~s}$ before the next stimulus. The threshold was taken as the median temperature at the time of the button press of four trials.

In the case of one patient (3), cold sensation was also measured with immersion of the hand up to the wrist in a circulating water bath at $20^{\circ} \mathrm{C}$ for $70 \mathrm{~s}$. At the end of this time, the patient rated the intensity of a stimulus rated as nonpainful or painful (intensity and unpleasantness), 
Table 2. Central pain characteristics of the patients in this series

\begin{tabular}{|c|c|c|c|c|c|c|c|c|c|c|c|c|}
\hline $\begin{array}{l}\text { Patient number, } \\
\text { diagnosis, lesion type }\end{array}$ & Distribution & $\begin{array}{l}\text { Clinical } \\
\text { hyperalgesia/ } \\
\text { allodynia }\end{array}$ & $\begin{array}{l}\text { Descriptors: } \\
\text { mechanical }\end{array}$ & Temperature & Movement & Tingle & Emotion & $\begin{array}{l}\text { No. McGill } \\
\text { descriptors }\end{array}$ & Depth & $\begin{array}{l}\text { VAS } \\
\text { intensity }\end{array}$ & VAS unpleasant & Treatment \\
\hline 8, CPSP, Vc only & $\begin{array}{l}\text { Lower leg, fore- } \\
\text { arm, V2-3 }\end{array}$ & $\begin{array}{l}\text { Hyperalgesia to } \\
\text { cold, pin, and } \\
\text { touch }\end{array}$ & Tugging, dull & Hot & & Tingle & & 4 & $\begin{array}{l}\text { Surface and } \\
\text { deep }\end{array}$ & 4.9 & NA & Nortriptyline $50 \times 4$ \\
\hline 3, CPSP, Vc only & $\begin{array}{l}\text { Ear, neck, arm } \\
\quad \text { and leg }\end{array}$ & Cold allodynia & Ache & $\begin{array}{l}\text { Cold, hot, } \\
\quad \text { burning }\end{array}$ & Throbbing & & Fatiguing & 6 & $\begin{array}{l}\text { Surface and } \\
\text { deep }\end{array}$ & 7.5 & 5.3 & $\begin{array}{l}\text { Neurontin } 200 \times 3 \text {, MS } \\
\text { contin } 30 \times 1+ \\
\text { PRN }\end{array}$ \\
\hline 18, CPSP, Vc plus & $\begin{array}{l}\text { Arm and leg } \\
\text { excluding } \\
\text { hand and } \\
\text { foot }\end{array}$ & $\begin{array}{l}\text { Allodynia to cold, } \\
\text { touch, joint } \\
\text { movement }\end{array}$ & $\begin{array}{l}\text { Pricking, pinching, } \\
\text { squeezing }\end{array}$ & $\begin{array}{l}\text { Hot, burning, } \\
\text { cold }\end{array}$ & Throbbing & & Frightful, fatiguing & & & 8.5 & 7 & $\begin{array}{r}\text { Neurontin } 300 \times 3 \\
\text { baclofen } 10 \times 3\end{array}$ \\
\hline $\begin{array}{l}\text { 13, central dysesthesia } \\
\text { syndrome, Vc plus }\end{array}$ & $\begin{array}{l}\text { Volar arm, pos- } \\
\quad \text { terior leg }\end{array}$ & $\begin{array}{l}\text { Paresthesias on joint } \\
\text { or whole body } \\
\text { movement }\end{array}$ & & & & Tingle & $\begin{array}{l}\text { Frightful, cruel, } \\
\text { fatiguing }\end{array}$ & 4 & & $0 / 10$ & $\begin{array}{l}\text { Unpleasant tingling } \\
\text { specifically not } \\
\text { painful }\end{array}$ & \\
\hline
\end{tabular}

as appropriate (Price et al., 1994). Before the introduction of quantitative thermal sensory testing, cold sensation was assessed in one patient only by contact cooling with a brass rod or liquid cooling with a drop of isopropyl alcohol and acetone, at room temperature. Warm stimuli were not applied in this patient. Stimuli on the affected side were described with respect to the "unaffected" side.

Heat pain and cold pain sensations. After determination of the innocuous thermal thresholds, the same protocol was used to determine heat pain and cold pain thresholds. The thermal probe started at an adapting temperature of $35^{\circ} \mathrm{C}$ (heat pain) or $30^{\circ} \mathrm{C}$ (cold pain), from which the temperature increased (decreased) at a rate of $1^{\circ} \mathrm{C} / \mathrm{s}$. The subjects were instructed to push the response button as soon as they first felt pain. After the subjects pressed the button or the temperature reached $50^{\circ} \mathrm{C}\left(0^{\circ} \mathrm{C}\right)$, the probe temperature returned to the adapting temperature for an interstimulus interval of 25-30 s. Pain threshold was taken as the median temperature at the time of the first button press of four trials for each stimulus series.

Tactile threshold. A Semmes-Weinstein monofilament kit (Stoelting, Wood Dale, IL) was used to test for tactile threshold on the dorsum of the hands or the dorsum of the feet, using a classic method of limits protocol (Essick, 1992).

Brushing allodynia. Manual testing consisted of brushing with two types of brushes: (1) a camel's hair paint brush, exerting $\sim 10 \mathrm{~g}$ of force when stroked across the skin and (2) a stiffer paint brush, exerting $\sim 90 \mathrm{~g}$ of force. Tactile allodynia was deemed present if brushing with either type of brush evoked sensations described as painful or uncomfortable when applied to the affected side of the body. Such stimuli were never described in such terms when applied on the unaffected side of the patients or when testing people with normal cutaneous sensitivity.

Statistical analysis of quantitative sensory testing within subjects. To evaluate thermal sensitivity, we used a value of the mean plus or minus two SDs outside a normal range as the criterion of an abnormal threshold. The values tested in this way included both absolute values (e.g., the actual threshold) and difference between the affected and unaffected side (e.g., the laterality difference score). For the thermal thresholds, normative data were taken from a database provided by MEDOC (Durham, NC), which separates according to sex and age by decade.

\section{PET scanning and analysis}

Brain activation was assessed by measuring relative changes in cerebral blood flow (CBF) with $\mathrm{H}_{2}{ }^{15} \mathrm{O}$ PET using a standard, single-subject protocol (Chmielowska et al., 1998, 1999). In brief, the subject was placed in the PET scanner (GE Advance; General Electric, Milwaukee, WI), and transmission scans were performed for attenuation correction during image reconstruction. A sham scan (saline injection) was performed to minimize anxiety associated with the PET scan. Thereafter, each PET scan was initiated after intravenous bolus injection of $10 \mathrm{mCi} \mathrm{H}_{2}{ }^{15} \mathrm{O}$, with data acquisition (three-dimensional mode with septa retracted) during the $60 \mathrm{~s}$ after tracer arrival in the brain. The subject had a total of 15 PET scans. The subject was scanned during three different stimulus conditions: (1) rest (no somatosensory stimulation), (2) $20^{\circ} \mathrm{C}$ waterbath stimulation on the affected side, and (3) $20^{\circ} \mathrm{C}$ waterbath stimulation on the unaffected side. These stimuli are described above. Each scanning condition was repeated five times in pseudorandom order.

\section{Image processing and analysis}

Structural MRI scans were used for transformation of PET data into standard stereotactic space (Collins et al., 1993). After spatial normalization, background correction, and movement correction, PET data were smoothed with a $10 \times 10 \times 10 \mathrm{~mm}$ Gaussian filter to minimize spatial variability still further (Chmielowska et al., 1998). To minimize variability produced by global CBF changes, each PET scan was normalized to gray matter values by dividing each voxel value by the average of whole brain CBF.

Standard general linear modeling techniques were used to identify activation that was significantly related to perceived pain intensity. To minimize the impact of multiple comparisons, statistical probabilities of activations were calculated based on spatial extent of clusters of voxels exceeding a T > 3.1 (Friston et al., 1994; Forman et al., 1995). Based on the smoothness of the image and the voxel dimensions, clusters $>318$ voxels $(2 \times 2 \times 2 \mathrm{~mm})$ were considered statistically significant $(p<$ $0.05)$.

A repeated-measures ANOVA was used to directly compare the magnitude of activation between the affected and unaffected primary sensorimotor cortices. To avoid confounds attributable to differences in cluster sizes, regions of interest were determined by the locations of local maxima within each (affected, unaffected) cluster of activation in the primary sensorimotor cortices.

\section{Results}

These studies were performed in patients with CPSP $(n=3)$ or central dysesthesia syndrome $(n=1)$ secondary to small infarcts of the posterior thalamus. These patients were selected from a group of patients with central pain or sensory abnormalities referred to Dr. Lenz. CPSP or central dysesthesia syndrome was diagnosed by an indisputable stroke episode and by exclusion of other nociceptive or neuropathic mechanisms of the pain or dysesthesias (Beric et al., 1988; Casey, 1991; Vestergaard et al., 1995; Boivie, 1999). Patients had radiologically identified lesions of the posterior thalamus contralateral to their symptoms but no other lesions of the pain or somatosensory systems, as broadly defined (Mountcastle, 1984; Davis, 2000; Rainville et al., 2000). Some MR images demonstrated unidentified bright objects, which are markers of hypertension in patients with stroke (Kertesz et al., 1988).

\section{Clinical features}

The clinical pain features of these four patients are given in Table 2. The three patients with CPSP (patients 3, 8, and 18) all described chronic pain, whereas the patient with the central dyses- 


\section{8 'Vc only' CPSP}
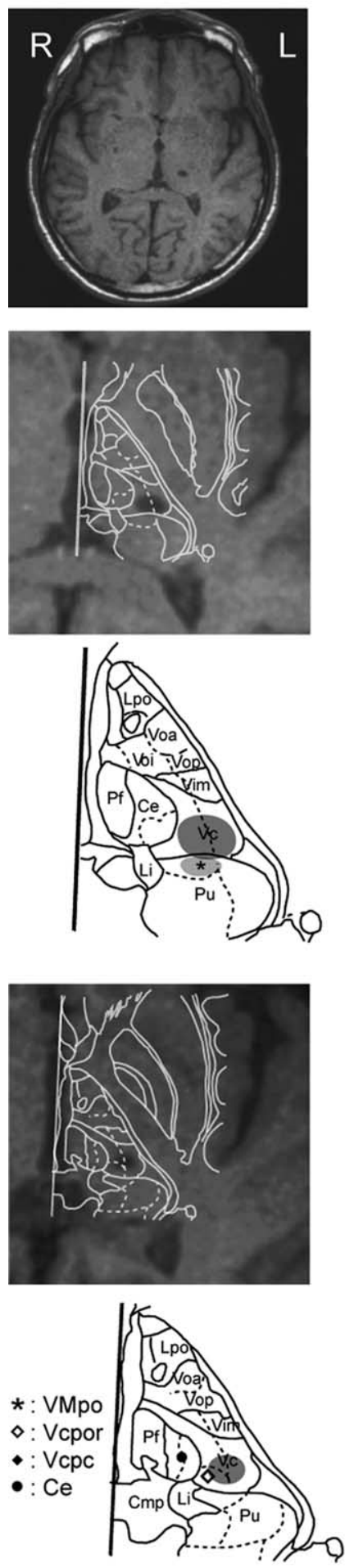

3 'Vc only' CPSP
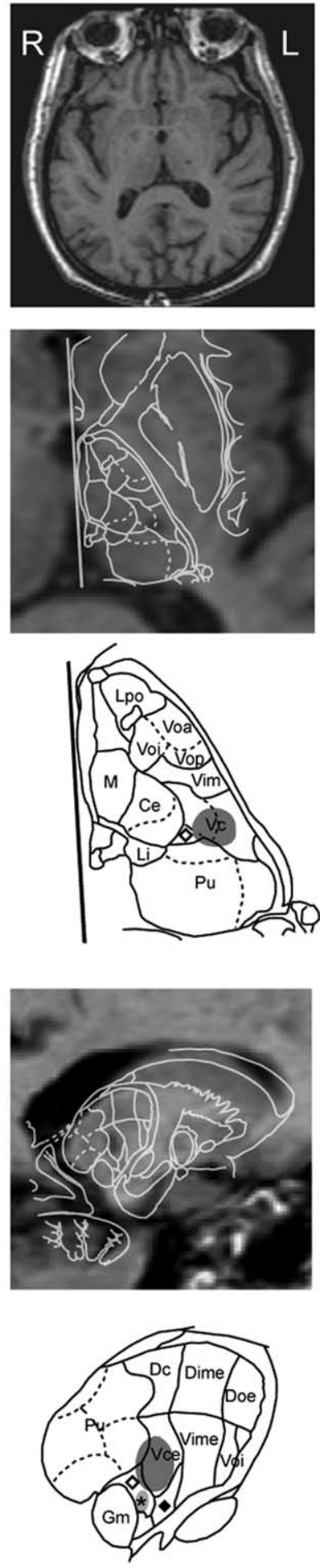

18 'Vc plus' CPSP
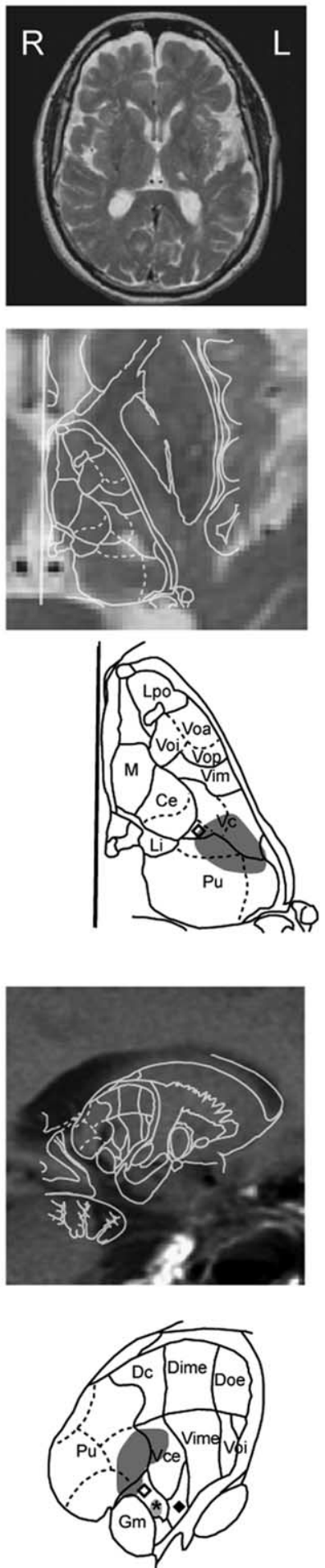

13 'Vc plus' Central Dysesthesia
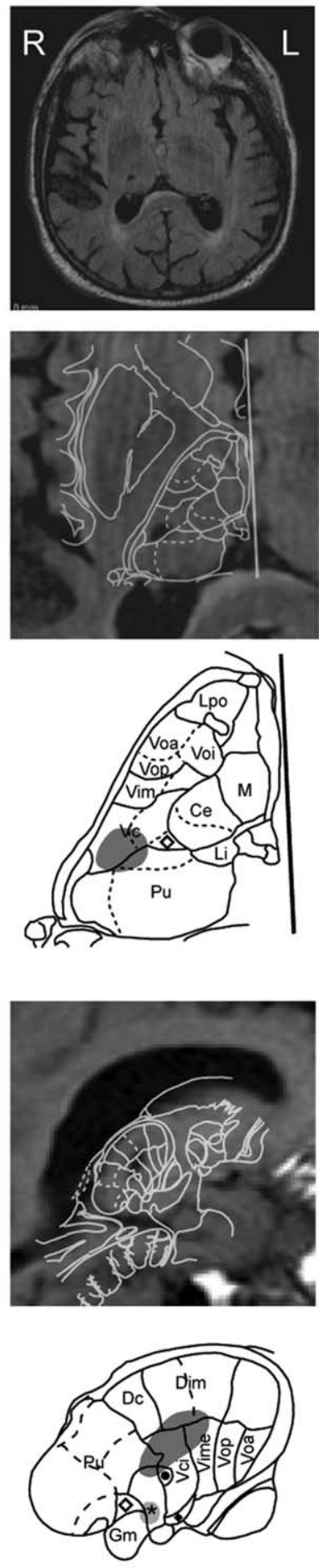

Figure 1. Locations of the thalamic lesions. Images taken through the center of these lesions in the axial and sagittal planes are shown through the whole brain and thalamus plus basal ganglia in rows 1,2 , and 4 . In keeping with radiologic convention, the left $(\mathrm{L})$ side of the brain is shown on the right $(\mathrm{R})$ side of the image in this figure, as shown by the $\mathrm{L}$ in the top row of the figure. Axial images of the lesions are shown in row 2 for all patients and in row 4 for patient 8 . The sagittal images of patients 3,13, and 18 are shown in row 4 . Each of these images is overlaid with the outline of the appropriate atlas map, as described in Materials and Methods (Schaltenbrand and Bailey, 1959). Rows 3 and 5 show the outlines minus the images for the corresponding panels in rows 2 and 4, respectively. In these images, the areas with the dark stipple are the lesions, and those indicated by the light stipple and the star are the locations of thalamic nucleus VMpo. Lpo, Nucleus lateropolaris; Voa nucleus ventral oral anterior; Voi, nucleus ventral oral internal; Vop, nucleus ventral oral posterior; Vim, nucleus ventral intermediate; Pf, parafascicular nucleus; Ce, nucleus central medial; Li, nucleus limitans; Pu, pulvinar; M, medial dorsal nucleus; Vcpor, nucleus ventral caudal portae; Vcpc, nucleus ventral caudal parvocellular; Cmp, posterior commissure; Dc, lateral posterior nucleus; Dime, dorsal intermediate external; Doe, dorsal oral external; Vime, nucleus ventral intermediate external; Vce, nucleus ventral caudal external; $\mathrm{Gm}$, medial geniculate nucleus; Dim, nucleus dorsal intermediate; Vci, nucleus ventral caudal internal. 


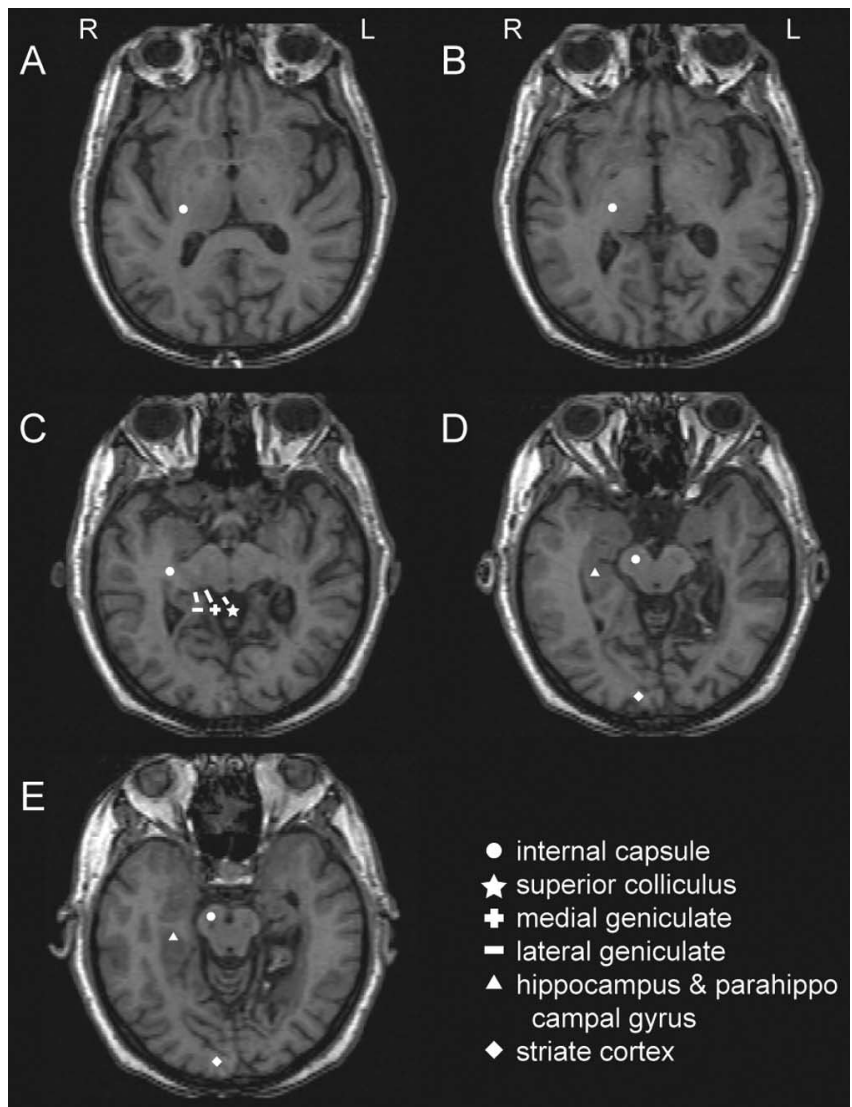

Figure 2. Anatomic locations of the stroke in patient 3, which involved extrathalamic structures. The lesion in this patient included the hippocampus, parahippocampal gyrus, and occipital cortex but no structures in the somatic sensory system, except the thalamic lesion shown in Figure 1 and in the top left panel of this figure. $\boldsymbol{A}-\boldsymbol{E}$, Note that the internal capsule in the more superior cuts $(\boldsymbol{A}-\boldsymbol{C})$ becomes the cerebral peduncles in the lower cuts $(\boldsymbol{D}-\boldsymbol{E})$. L, Left; R, right.

thesia syndrome (13) described unpleasant tingling sensations that were nonpainful, even on specific inquiry. All three patients with CPSP described the pain in terms of both temperature (hot, burning, cold) and heavy mechanical sensations (dull, aching, squeezing). On clinical evaluations, all three patients reported pain in response to cool stimuli that were not normally painful (cold allodynia: patients $3,8,18$ ) (see Table 2). Two of the three patients (patients 8 and 18) demonstrated tactile allodynia. These features are similar to other studies of patients with CPSP (Boivie and Leijon, 1991; Andersen et al., 1995; Bowsher et al., 1998).

\section{Radiologic tests}

The thalamic strokes in all four cases were located in the posterior lateral thalamic territory of the thalamogeniculate and posterior thalamic perforating vessels (Fig. 1, top row) (Krayenbuhl and Yasargil, 1972; Erdem et al., 1993). These are branches of the posterior communicating artery and of the posterior cerebral artery both proximal and distal to the junction of the two arteries.

The stroke in patient 3 also involved nonthalamic territories, including the posterior medial aspect of the temporal lobe and the medial occipital lobe (Fig. 2). The occlusion in this stroke may have involved the distal posterior cerebral arterial branches as well as a perforator supplying the area of the thalamic lesion (Figs. $1,2)$. This is consistent with the patient's neurologic exam, which demonstrated a hemifield visual loss on the affected side (Table 1). The thalamic component aside, this stroke spared the midbrain and diencephalon, including the superior colliculus, poste- rior limb of the internal capsule/cerebral peduncle, and medial and lateral geniculate as shown in Figure 2.

All four patients had lesions within the posterior half of $\mathrm{Vc}$; in two patients, the thalamic lesion was limited to ventral Vc ("Vconly" lesions; patients 3 and 8). In the other two, the lesions were located in dorsal Vc and extended posterior to Vc proper into the Vc portae and pulvinar oral nuclei, which receive STT input ("Vc-plus" lesions; patients 13 and 18) (Mehler et al., 1960; Mehler, 1962; Apkarian and Hodge, 1989).

When expressed as a proportion of the anterior commissureposterior commissure (ACPC) line, the maximum axial dimension of these lesions was between 0.17 and 0.37 , whereas maximum sagittal dimensions were between 0.25 and 0.38 . When expressed as a percentage of the volume of Vc (see Table 4), the volume of the lesion within Vc was larger for Vc-only lesions (16-20\%) than for Vc-plus lesions (12-15\%) but was similar to the volume posterior to Vc in Vc-plus lesions (16-20\%).

$\mathrm{Vc}$-plus lesions involved structures posterior to $\mathrm{Vc}$ and thus might have involved VMpo. The estimated position of VMpo is indicated in the appropriate sections of Figure 1 (see Materials and Methods) (Blomqvist et al., 2000; Montes et al., 2005). None of these lesions had involvement of VMpo because they were located anterior to VMpo (Vc-only lesions), or lateral and dorsal (Vc-plus lesions). These patients demonstrate that Vc-only and Vc-plus lesions in the setting of a thalamic stroke are sufficient to cause CPSP or the central dysesthesia syndrome.

In Figure 1, the difference in vertical location of the anterior and posterior commissures on the axial scans was $<3 \mathrm{~mm}$ in all four cases, corresponding to an angle of $<13.5^{\circ}$ relative to the plane of the scan, approximately parallel to the ACPC line. This vertical distance between the commissures at right angles to the ACPC line is within errors introduced by the range of thickness for slice intervals of the Schaltenbrand atlas. It is also within the uncertainty introduced by the slice thickness and the resolution of the older MRI scans, which can be seen by the pixelation in Figure 1 (row 2, patient 18) (Schaltenbrand and Bailey, 1959).

\section{Formal sensory testing}

Quantitative sensory testing was performed in all patients except patient 8 . This patient was evaluated by mixed quantitative and qualitative sensory testing early in the course of this study. Although qualitative sensory tests cannot be used to describe the extent of a perceptual abnormality, they have been used to establish the presence of altered sensation, as in previous studies (Nathan and Smith, 1996).

Patient 8 rated three innocuous cool stimuli and had diminished responses to one (Table 3, drop of acetone) and pain in response to another (brass rod). Among patients in whom quantitative sensory testing was performed, two had cold and warm hypoesthesia bilaterally (patients 13 and 18), consistent with evidence of abnormal thermal sensation ipsilateral to the stroke in patients with CPSP (Boivie et al., 1989; Vestergaard et al., 1995). Patient 3 demonstrated no abnormality of innocuous cold sensation and the smallest Vc-only lesion, which suggests that sensory impairment depends on a minimal lesion volume in Vc (Table 3) (Duncan et al., 1993).

Cold pain sensation was assessed in all four patients (Table 3 ). Patient 8 (Vc only) showed cold allodynia in response to the brass bar, which is nonpainful in control subjects (Lenz et al., 1993a). Among three patients tested with quantitative testing, one patient had cold allodynia (patient 18), and one had hypoalgesia (patient 13). The fourth patient (patient 3 ) had cold hyperalgesia as indicated by ratings of the intensity and unpleasantness of a $20^{\circ} \mathrm{C}$ 
Table 3. Results of somatic sensory testing of the patients in this series

\begin{tabular}{|c|c|c|c|c|c|c|c|c|c|c|c|c|c|}
\hline $\begin{array}{l}\text { Patient number, } \\
\text { lesion type }\end{array}$ & $\begin{array}{l}\text { Warm } \\
\text { threshold } \\
\text { unaffected }^{a}\end{array}$ & $\begin{array}{l}\text { Warm } \\
\text { threshold } \\
\text { affected }\end{array}$ & $\begin{array}{l}\text { Cold } \\
\text { threshold } \\
\text { unaffected }\end{array}$ & $\begin{array}{l}\text { Cold } \\
\text { threshold } \\
\text { affected }\end{array}$ & $\begin{array}{l}\text { Cold stimuli, } \\
\text { response }^{b}\end{array}$ & $\begin{array}{l}\text { Cold pain } \\
\text { threshold: } \\
\text { unaffected }\end{array}$ & $\begin{array}{l}\text { Cold pain } \\
\text { threshold: } \\
\text { affected }\end{array}$ & $\begin{array}{l}\text { Heat pain } \\
\text { threshold: } \\
\text { unaffected }\end{array}$ & $\begin{array}{l}\text { Heat pain } \\
\text { threshold: } \\
\text { affected }\end{array}$ & Brush & Puff of air & $\begin{array}{l}\text { Vibration } \\
\text { unaffected }\end{array}$ & $\begin{array}{l}\text { VF detect (unaff } \\
\text { vs aff) }\end{array}$ \\
\hline 8 , Vc only & Leg NA & NA & NA & NA & $\begin{array}{l}\text { Brass rod, "rubbing a } \\
\text { sore" } \\
\text { Alcohol drop, ND } \\
\text { Acetone drop, less } \\
\text { intense than unaff }\end{array}$ & NA & NA & NA & NA & Normal & Bothersome & $\begin{array}{l}\text { Vibration aff ND } \\
\text { at } 128,256 \\
\mathrm{~Hz}\end{array}$ & Leg (1.41 vs $4.2 \mathrm{~g}$ ) \\
\hline 3, Vc only & Hand 36.4 & 36.7 & 30.0 & 29.9 & $\begin{array}{l}20^{\circ} \mathrm{C} \text { waterbath, Painful } \\
\text { aff }(4.8 \pm 0.75)> \\
\text { unaff }(3.2 \pm 0.95, p \\
=0.008, t \text { test }) \text { hyper- } \\
\text { alg }\end{array}$ & 8.6 & 6.3 & 50 & 46.8 & Painful & NA & NA & NA \\
\hline $18, \mathrm{Vc}$ plus & Hand 43.4 & $\begin{array}{l}44.8 \text { hy- } \\
\text { poesth } \\
\text { bilat }\end{array}$ & 24.3 & $\begin{array}{l}25.4 \text { hy- } \\
\text { poesth } \\
\text { bilat }\end{array}$ & NA & 15.3 & 20.9 hyperalg & $>50$ & $>50$ & Painful & NA & NA & $\begin{array}{l}\text { Foot sole }(0.45 \mathrm{vs} \\
1.04 \mathrm{~g})^{c}\end{array}$ \\
\hline 13, Vc plus & $\begin{array}{l}\text { Plantar foot } \\
\quad 48.5\end{array}$ & $\begin{array}{l}48 \text { hypoesth } \\
\text { bilat }\end{array}$ & 21 & $\begin{array}{l}24.1 \text { hy- } \\
\text { poesth } \\
\text { bilat }\end{array}$ & NA & 5.9 & $\begin{array}{c}<0 \text { hypoalg (aff } \\
\text { sens }<\text { unaff) }\end{array}$ & 48.5 & 48.4 & Nonpainful & NA & NA & 1.0 vs 1.4 \\
\hline
\end{tabular}

NA, Not available; ND, stimulus not detected; unaff, unaffected; aff, affected; VF, von Frey; sens, sensitivity; hypoesth bilat, hypoesthesia bilaterally; hyperalg, hyperalgesia; hypoalg, hypoalgesia.

${ }^{a}$ Thresholds (in ${ }^{\circ} \mathrm{C}$ ) are shown for each of the four thermal modalities (cool, warm, etc.) at sites as indicated in row 2. hypoesth/hypoalg indicates that the threshold is significantly different from the normal range (Greenspan et al., 2004). Hypoesth bilat indicates that the threshold values were significantly different from the normal range on both sides. Sens aff $<$ or $>$ unaff indicates that the threshold on this side indicated greater, or lesser, sensitivity to that stimulus modality than the other side.

${ }^{b}$ The responses to application of a brass rod at room temperature, a drop of alcohol, and a drop of acetone to the affected side are stated with respect to the other (unaffected) side. On the unaffected side, the stimuli were routinely detected and rated as nonpainful cold.

'Only available von Frey data.

Table 4. Dimensions of thalamic lesions and results of somatic sensory testing in this series

\begin{tabular}{|c|c|c|c|c|c|c|c|c|c|c|c|}
\hline $\begin{array}{l}\text { Patient } \\
\text { number }\end{array}$ & Diagnosis & Lesion class & $\begin{array}{l}\text { Volume } \\
\text { in } V c^{a}\end{array}$ & $\begin{array}{l}\text { Volume } \\
\text { posterior } \\
\text { to Vc }\end{array}$ & Clinical hypersensitivity & $\begin{array}{l}\text { Clinical pain } \\
\text { descriptors (VAS } \\
\text { intensity/unpleasant) }\end{array}$ & Warm threshold & $\begin{array}{l}\text { Heat pain } \\
\text { sensation }\end{array}$ & Cold sensation & $\begin{array}{l}\text { Cold pain } \\
\text { sensation }\end{array}$ & Tactile sensation \\
\hline 8 & CPSP & Vc only & $20 \%$ & $2 \%$ & $\begin{array}{l}\text { Hypersensitivity to pin } \\
\text { and touch }\end{array}$ & $\begin{array}{l}\text { Thermal, tingle (4.9/ } \\
\text { NA) }\end{array}$ & NA & NA & $\begin{array}{l}\text { Hypoesthesia to } \\
\text { acetone drop }\end{array}$ & $\begin{array}{l}\text { Hyperalgesia to } \\
\text { cold bar }\end{array}$ & $\begin{array}{l}\text { Hypoesthesia to VF, } \\
\text { tuning fork, allo- } \\
\text { dynia to air puff }\end{array}$ \\
\hline 3 & CPSP & Vc only & $16 \%$ & $2 \%$ & Cold allodynia & $\begin{array}{l}\text { Thermal, movement, } \\
\text { emotion (7.5/5.3) }\end{array}$ & Normal & WNL & Normal & $\begin{array}{l}\text { Hyperalgesia to } \\
\text { cold waterbath }\end{array}$ & Allodynia \\
\hline 18 & CPSP & Vcplus & $15 \%$ & $20 \%$ & $\begin{array}{l}\text { Allodynia to cold, touch, } \\
\text { joint movement }\end{array}$ & $\begin{array}{l}\text { Thermal, movement, } \\
\text { emotion (8.5/7) }\end{array}$ & Hypoesth bilat & WNL & Hypoesth bilateral & Hyperalgesia & $\begin{array}{l}\text { Hypoesthesia to VF, } \\
\text { allodynia }\end{array}$ \\
\hline 13 & $\begin{array}{l}\text { Central dysesthesia } \\
\text { syndrome }\end{array}$ & Vcplus & $12 \%$ & $16 \%$ & $\begin{array}{l}\text { Paresthesias on joint or } \\
\text { whole body move- } \\
\text { ment }\end{array}$ & $\begin{array}{l}\text { Tingle, emotion } \\
(0 / 10)\end{array}$ & Hypoesth bilat & WNL & Hypoesth bilateral & Hypoalgesia & $\begin{array}{l}\text { Hypoesthesia to VF, no } \\
\text { hypersensitivity }\end{array}$ \\
\hline
\end{tabular}

All volumes apply to lesions and are expressed as a percentage of the volume of $\mathrm{Vc}$. All results refer to the affected side, unless indicated as bilateral. Other conventions are as in Tables 2 and 3 . NA, Not available; ND, stimulus not detected WNL, within normal limits; VF, von Frey; VAS, visual analog scale; hypoesth bilat, hypoesthesia bilaterally.

${ }^{a}$ Volumes of $V c$ and lesions estimated as $\Sigma$ by slice of (area of structure $\times$ slice thickness).

waterbath on the affected side versus the unaffected side. In this patient, the $20^{\circ} \mathrm{C}$ waterbath applied to the unaffected side was mildly painful, which was sometimes observed in healthy subjects (Casey et al., 1996; Sarlani et al., 2003). All three of these patients with $\operatorname{CPSP}(8,3$, and 18) also had clinical evidence of cold allodynia.

Heat and painful heat sensations were normal in these patients. Only the two patients with Vc-plus lesions had bilateral hypoesthesia for warmth (patients 13 and 18). Heat pain sensation was normal in all patients tested.

Tactile sensation was impaired on the affected side in all patients who were assessed for tactile sensation with von Frey hairs (patients 8, 13, and 18) (Table 3). The impairment was less in patients 13 and 18 than in patient 8 , which may be consistent with the larger volume of the lesion in Vc of patient 8 versus patients 13 and 18 (Table 4). Tactile allodynia was found in all three patients with CPSP but not in the patient with central dysesthesia syndrome (patient 13) (Table 3). Therefore, the movement allodynia found in patients 8 and 18 may have been caused by activation of cutaneous afferents by deformation of the skin secondary to movement. Movement hypersensitivity in patient 13 is more likely caused by activation of deep afferents, because there was no tactile hypersensitivity in this patient.

In summary, innocuous cold sensation was impaired in all four patients, except the one with the smallest lesion. Cold pain sensation was altered in all four. Tactile sensation was impaired on the affected side in all three patients who were tested. Nonpainful heat sensation was impaired in patients with Vc-plus lesion and painful heat sensation was not impaired in any patient.

\section{Correlation between stroke location, clinical evaluation, and formal sensory testing}

Both patients with Vc-only lesions had CPSP, including the patient with the smallest lesion. Among the two patients with Vcplus lesions (13 and 18), patient 13 had the central dysesthesia syndrome. In contrast, patient 18 had the most severe CPSP in the present series, as demonstrated by the highest visual analog scale rating and the highest number of McGill descriptors (Table 2) (Torgerson et al., 1988).

The only feature common to the four thalamic lesions presented here is that they involved posterior Vc (Jones, 1985; Lenz et al., 1988b). All patients tested had abnormalities of the cold pain and tactile sensations, which strongly suggests that nucleus Vc subserves these sensations.

All four patients had involvement of both the medial and lateral aspects of $\mathrm{Vc}$, representing the face and body, respectively (Lenz et al., 1988a). All patients had sensory symptoms involving arm and leg, whereas patients with Vc-only lesions (patients 3 and 8) also had involvement of face (Table 2). There was no apparent difference in the medial extent of the lesion in Vc (Fig. 1) between these patients with facial symptoms and those without (patients 13 and 18). However, the Vc-plus lesions were both 


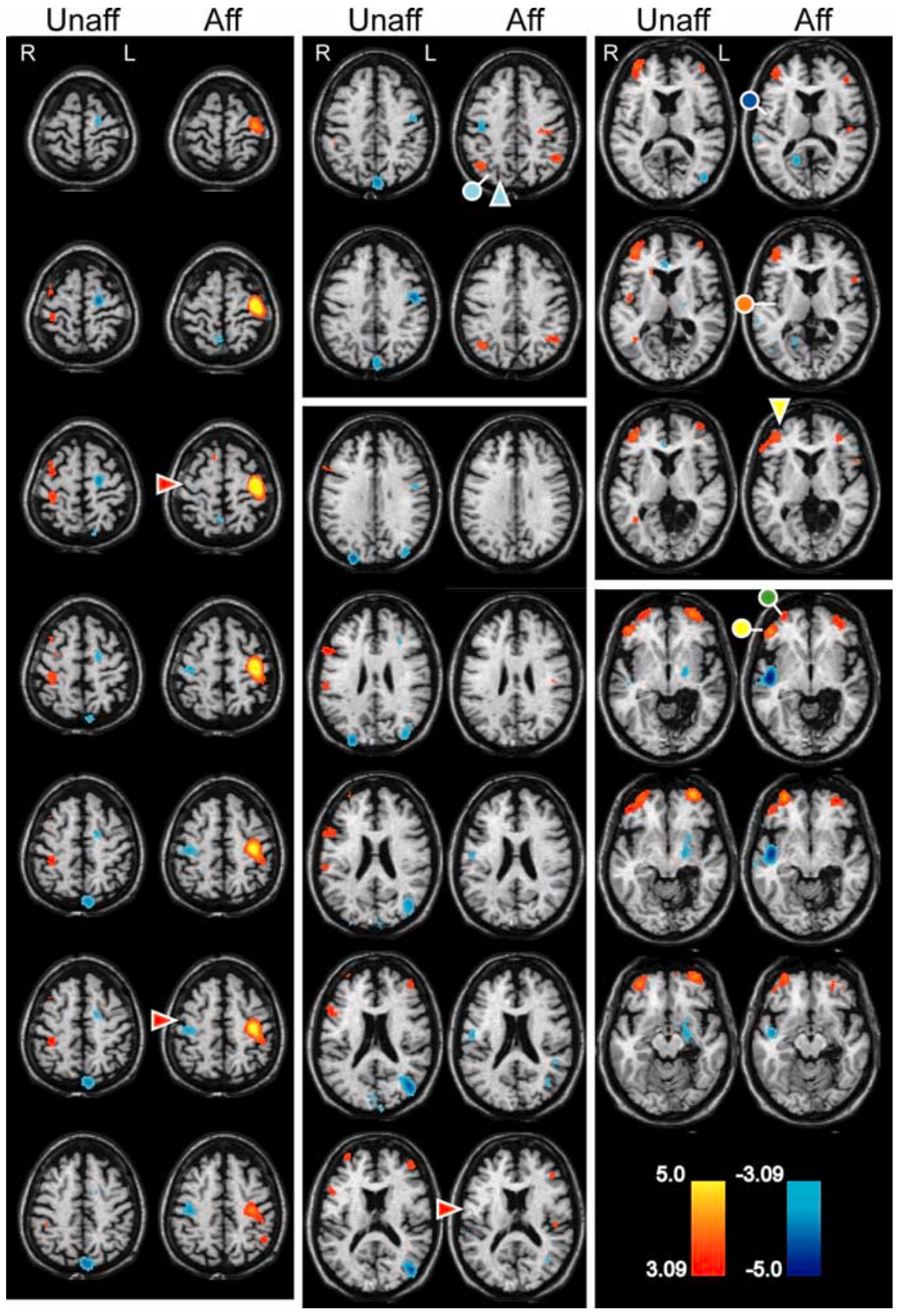

Figure 3. Blood flow consequences of $20^{\circ} \mathrm{C}$ waterbath stimulation of the left [clinically affected (Aff)] and right [unaffected (Unaff)] hands in a patient with (PSP after a right thalamic infarction (patient 3). PET blood flow data are displayed in color on the structural magnetic resonance images as appropriate (see labels). The color bars indicate $t$ scores, red-yellow for increases and blue for decreases in blood flow with respect to the rest conditions. Colored symbols indicate named sulci (arrowhead) and gyri (circles) as identified in the text. As in Figure 1, the patient's left $(\mathrm{L})$ is shown on the readers right $(\mathrm{R})$, as indicated by the $\mathrm{L}$ in the figure.

dorsal to the Vc only, which suggests that impaired facial sensation may be related to the ventral location of the facial representation in human Vc (Lenz et al., 1988a).

\section{Functional imaging}

A single-subject PET protocol was performed with immersion of the hand in a $20^{\circ} \mathrm{C}$ waterbath in a patient with cold allodynia both clinically and on sensory testing (patient 3). Activations are shown in Figure 3 for stimulation of the affected and unaffected hands, as labeled. Stimulation of the allodynic hand produced strong activation of sensorimotor cortex around the contralateral central sulcus (red arrowheads, left column and bottom of middle column) and inhibition around the central sulcus on the ipsilateral side. There was less pronounced activation both of the inferior frontal gyrus (yellow circle, right column, top four images) below the inferior frontal sulcus (yellow arrowhead) and of the prefrontal cortex, bilaterally (green circle, right column).

Among more posterior structures, there was activation of the secondary somatic sensory cortex/inferior parietal lobute (S2/IPL) region contralaterally, S2 specifically. S2 is indicated by a dark blue circle (Fig. 3, top right column), and IPL is indicated by a light blue circle below the intraparietal sulcus (light blue arrowhead, top middle column). Finally, there was increased blood flow in the contralateral insula/retroinsula and decreased blood flow in the ipsilateral insula/retroinsula (orange circle, right column, second image down). With stimulation of the unaffected hand, there was a similar pattern of activation involving contralateral sensorimotor cortex, inferior frontal gyrus, bilateral prefrontal cortex, inferior parietal lobule/secondary somatosensory cortex (S2), insula/ retroinsula, and decreased blood flow in the ipsilateral insula/retroinsula (these structures defined by circles and arrows in the figures).

Direct statistical comparisons revealed that stimulation of the affected side produced significantly greater activation of the contralateral sensorimotor cortex than did stimulation of the unaffected side. A two-way repeated-measures ANOVA confirmed that relative blood flow in the sensorimotor cortex (1) was higher ipsilateral to the lesion during both rest and stimulation (main effect of hemisphere, $\left.F_{(1,5)}=49.73, p<0.0009\right)$, (2) was elevated in both hemispheres during stimulation (main effect of stimulation, $F_{(1,5)}=$ 46.62, $p<0.0010$ ), and (3) increased significantly more in the presence of stimulation in the hemisphere ipsilateral to the lesion than in the other hemisphere (interaction, $\left.F_{(1,5)}=10.99, p<0.0211\right)$. These results demonstrate that in patient 3 , immersion of the affected hand in $20^{\circ} \mathrm{C}$ water produced hyperalgesia and significantly increased activation in the contralateral sensorimotor cortex when compared with stimulation of the other hand.

\section{Discussion}

We have now tested the hypothesis that thalamic lesions leading to loss of cold sensation and to CPSP include the region posterior to Vc, including VMpo. In the present study, all lesions had involvement of the posterior aspect of $\mathrm{Vc}$, and all patients tested had alterations of tactile and cold pain sensations. Cold hypoes- 
Table 5. Functional imaging results in response to cold stimuli in several studies

\begin{tabular}{|c|c|c|c|c|c|c|}
\hline & Cold pain activations & Control painful cold & Patient 3 unaffected & Wallenberg unaffected & Patient 3 affected & Wallenberg affected \\
\hline $\mathrm{ACC}$ & NA & $\mathrm{B} \uparrow$ & & & & $I \downarrow$ \\
\hline SM & NA & $C \uparrow$ & $C \uparrow$ & & $C \uparrow, I \downarrow$ & $C \uparrow$ \\
\hline SPL & NA & & & & & \\
\hline $\mathrm{IPL} / \mathrm{S2}$ & C $6 / 12$ & & $C \uparrow$ & $C \uparrow$ & $C \uparrow, I \downarrow$ & $B \uparrow$ \\
\hline Insula/RI & C 4/12, I4, B 0 & $C \uparrow$ & $C \uparrow$ & & $C \uparrow, I \downarrow$ & $C \uparrow$ \\
\hline IFG & & $B \uparrow$ & $C \uparrow$ & $\mid \uparrow$ & $B \uparrow$ & $C \uparrow$ \\
\hline PFC & NA & $\mathrm{I} \uparrow$ lat & $\mathrm{B} \uparrow$ & & $B \uparrow$ & \\
\hline PMC & NA & $C \uparrow$ & & & & \\
\hline$O C$ & NA & & $\mathrm{B} \downarrow$ & $\mathrm{B} \downarrow$ & $B \downarrow$ & $B \downarrow$ \\
\hline$B G$ & $\mathrm{C} 0 / 12,12, \mathrm{~B} 2$ & & $\mathrm{I} \downarrow$ & $\mid \downarrow$ & & \\
\hline Thalamus & C 4/12, I2, B 3 & $1 \uparrow$ & & & & $C \uparrow$ \\
\hline MTL & NA & & I $\downarrow$ & & $\mid \downarrow$ & \\
\hline
\end{tabular}

The first data column identifies the number of subjects showing activation contralateral (C), ipsilateral (I), and bilateral (B) to a painful cold contact stimulus (see abbreviations below) (Davis et al., 1998). Note that only the four brain regions identified were evaluated in the Davis study. The second column shows control results for the forebrain structures activated by immersion of the hand in a painfully cold $\left(6^{\circ} \mathrm{C}\right.$ ) waterbath stimulus (Casey et al., 1996$)$. The third and fifth columns give activations in response to immersion of the unaffected and affected hand in a $20^{\circ} \mathrm{C}$ waterbath, respectively (Fig. 3, patient 3). The fourth and sixth columns lists the activations related to stimulation of the unaffected and affected side of patients with CPSP secondary to the Wallenberg syndrome (lateral medullary infarct) in response to the cold/mechanical stimulus described in Results (Peyron et al., 1998). BG, Basal ganglia; IFG, inferior frontal gyrus; insula/RI, insula/retroinsula; MFG, middle frontal gyrus; MTL, medial temporal lobe; OC, occipital cortex; PFC, prefrontal cortex; PMC, premotor cortex; SM, sensorimotor cortex; SPL, superior parietal cortex; NA, not available; lat, lateral.

thesia was observed in all cases, except the smaller of the Vc-only lesions, which suggests that sensory loss occurs only in lesions involving a minimum volume of Vc (Duncan et al., 1993). None of these lesions involved VMpo, which was located posterior to Vc-only lesions and ventral to Vc-plus lesions (Fig. 1) (Blomqvist et al., 2000). We conclude that lesions of Vc are sufficient to impair cold and tactile sensations and that thalamic lesions leading to CPSP do not necessarily include VMpo.

\section{Implications for sensory functions mediated through the medial lemniscus}

This study has demonstrated that tactile sensation was decreased in all patients tested, including patient 8 with the Vc-only lesion. Previous electrophysiological studies have provided strong evidence that neurons in $\mathrm{Vc}$, the terminus of the dorsal columnmedial lemniscus pathway, mediate the sensations evoked by tactile stimuli (Mountcastle, 1984; Lenz et al., 1988b; Ohara et al., 2004). Finally, all of these results are consistent with studies of spinal cord lesions, which demonstrate that the dorsal columns are essential for normal tactile sensation (Noordenbos and Wall, 1976; Nathan et al., 1986).

Patient 13 had the central dysesthesia syndrome and experienced dysesthesias in response to joint movement. This patient also had limited diminution of tactile perception without tactile allodynia, which suggests that deep afferents may mediate movement-evoked dysesthesias. The lesion in this patient included dorsal ventral intermediate and anterodorsal Vc, which may receive muscle afferent input via the medial lemniscus (Jones et al., 1982) although the Schaltenbrand atlas does not show anterodorsal Vc (Hirai and Jones, 1989). In these regions, neurons respond to joint movement, and stimulation evokes deep and movement sensations (Lenz et al., 1988a; Ohara et al., 2004). These observations suggest that input arising from deep afferents may be interrupted by the Vc-plus lesion in patient 13 , so that hypersensitivity to movement is mediated through the STT, which is another source of deep afferent information to Vc thalamus (Foreman et al., 1979; Leijon et al., 1989; Dougherty et al., 1992; Bowsher, 1996).

Implications for sensory functions mediated through the STT These results suggest the identity of regions that mediate painful and nonpainful stimuli of thermal and tactile modalities. Structures within and behind Vc contain both neurons that respond to nonpainful heat (Lenz et al., 1993b; Lee et al., 1999) and sites at which stimulation commonly evokes nonpainful heat sensations (Lenz et al., 1993a; Ohara and Lenz, 2003). In view of the present results, these previous studies suggest that the sensation of nonpainful heat is mediated through structures that are located posterior to $\mathrm{Vc}$.

Painful heat thresholds were normal in all patients tested. However, laser-evoked potentials, which are mediated through a nociceptive heat pathway, were diminished in a patient with a lesion of $\mathrm{Vc}$, which was much larger than the present lesions (Montes et al., 2005). These results suggest that the sensation of painful heat is impaired by larger lesions of Vc, by bilateral lesions, or by lesions of anterior and ventral Vc, which were spared by lesions in the present results. This is consistent with the broad distribution both of neurons responding to painful heat in Vc and of sites at which stimulation evokes painful heat (Lenz et al., 1993a; Ohara and Lenz, 2003).

The present results demonstrate that small lesions of posterior Vc alter the sensation of cold pain, whereas Vc-plus or larger Vc-only lesions are required to impair innocuous cold sensation. In these regions, neurons respond to painful and nonpainful cold, and microstimulation may evoke the sensation of cold or cold pain (Lenz et al., 1993b; Davis et al., 1999; Lee et al., 1999; Ohara and Lenz, 2003). The present lesion results suggest that small lesions of posterior Vc are sufficient to alter cold pain sensation, and larger lesions of $\mathrm{Vc}$ are required to impair cold sensation. Alternately, the location of the lesion within $\mathrm{Vc}$ may be the main determinant of altered sensation.

\section{Dimensions of lesions required to impair perception}

The discriminative aspect of somatic sensation can be measured in monkeys by the detection of an airpuff or a small temperature step that occurs on the baseline of a noxious thermal stimulus (Bushnell et al., 1983). This protocol has been used to apply graded stimuli to the perioral skin before and after injections of a local anesthetic into medial aspect of the ventral posterior nucleus (VPM). Single injections into VPM silenced neurons $2 \mathrm{~mm}$ ventral to the site of the injection but did not impair detection of any tactile, noxious heat, or noxious cold stimuli tested (Duncan et al., 1993). However, two or three separate, simultaneous injections into VPM decreased detection of all three modalities, which suggests that these are mediated by discrete anatomic elements within VP (Jones et al., 1982; Rausell et al., 1992; Patel et al., 2006).

The present study suggests that a Vc-only lesion of $\geq 16 \%$ of 
Vc, and perhaps as little as $12 \%$ (in Vc-plus lesions), is sufficient to impair discrimination of tactile sensation (Table 4). The sensation of cool or cold pain is impaired by a Vc-only lesion with a volume of $\geq 16 \%$. If the volume of the lesion in $\mathrm{Vc}_{\mathrm{c}}$ is $<16 \%$, extension of the lesion posterior to $\mathrm{Vc}$ with a volume $\geq 17 \%$ is sufficient to impair the sensation of cool or cold pain (Table 4). Human anatomic and physiologic studies have demonstrated the presence of thermal and pain-signaling pathways within the posterior aspect of $\mathrm{Vc}$ and within nuclei that are located posterior to Vc (Mehler, 1962; Lenz et al., 1993b; Ohara and Lenz, 2003).

This lesion volume-dependent impairment of sensations may be related to the monkey anatomic (Jones et al., 1982; Rausell et al., 1992; Patel et al., 2006) and human psychophysical subnuclear divisions (or elements) of modality specificity within Vc. (Jones et al., 1982; Rausell et al., 1992; Patel et al., 2006). These elements may also be the basis of separate, subnuclear thalamic networks for painful and nonpainful modalities (Apkarian et al., 2000).

\section{Functional imaging studies}

The largest PET study of CPSP-induced allodynia involved patients with a lateral medullary stroke (Wallenberg syndrome) (Peyron et al., 1998). The allodynic test stimulus was a cold/ mechanical stimulus described as "a cold non-noxious stimulus (ice in a flat plastic container)... moved slowly" over the skin. When this stimulus was used on the affected side, it produced activation of structures very similar to those activated in response to $20^{\circ} \mathrm{C}$ waterbath stimulation of the affected hand in the present study (Table 4) (Peyron et al., 1998) (see also Cesaro et al., 1991; Hirato et al., 1994).

The proposed relationship between the present single-subject protocol and the previous population protocol studies of CPSP must take account of intersubject variability. The betweensubjects variability of the response to contact cold/painful cold stimuli has been examined in a study of functional MRI activations in response to contact cold and cold pain stimuli (Davis et al., 1998). Given the variability of the response to cold between subjects, the similarity of the present results with the Wallenberg study is remarkable. It is remarkable that the increased sensorimotor blood flow evoked by a painful cold waterbath stimulus was found both in healthy controls and in patients with CPSP (Table 5).

The site of the thalamic lesions in CPSP and these imaging results suggest that both a lesion of $\mathrm{Vc}$, and sparing of parts of the STT-Vc-SI nociceptive system are essential for development of thalamic CPSP. Interactions between first-order thalamic relay nuclei, like Vc, and their cortical targets are highly specific. For example, if a thalamic region within Vc projects to the somatotopically appropriate area in SI, that cortical area projects back to the same thalamic region (Steriade et al., 1997; Sherman and Guillery, 2001). However, this specificity is not reflected in the connections to $\mathrm{Vc}$ from the thalamic reticular nucleus and from corticothalamic cells outside the somatotopically appropriate area.

A partial lesion of $\mathrm{Vc}$ may produce altered activity in these nonspecific connections to neurons and nuclei adjacent to the Vc lesion site and the areas with altered blood flow related to stimulation of Vc including S1, S2, M1, and ACC (Davis et al., 2000). Involvement of $\mathrm{Vc}$ and $\mathrm{S} 1$ is consistent with hypersensitivity to electrical stimulation of $\mathrm{Vc}$ and primary somatic sensory cortex, which produce pain more commonly in patients with central pain than those without (Katayama et al., 1994; Davis et al., 1996; Lenz et al., 1998; Nguyen et al., 2000; Brown and Barbaro, 2003).
Finally, lesions of sensorimotor cortex can dramatically relieve pain in patients with thalamic central pain (White and Sweet, 1969; Soria and Fine, 1991). The evidence of blood flow, stimulation, and lesion studies forcefully make the case that Vc and sensorimotor cortex are involved in CPSP resulting from small thalamic lesions.

\section{References}

Andersen P, Vestergaard K, Ingeman-Nielsen M, Jensen TS (1995) Incidence of post-stroke central pain. Pain 61:187-193.

Apkarian AV, Hodge CJ (1989) Primate spinothalamic pathways. III. Thalamic terminations of the dorsolateral and ventral spinothalamic pathways. J Comp Neurol 288:493-511.

Apkarian AV, Shi T, Bruggemann J, Airapetian LR (2000) Segregation of nociceptive and non-nociceptive networks in the squirrel monkey somatosensory thalamus. J Neurophysiol 84:484-494.

Beric A, Dimitrijevic MR, Lindblom U (1988) Central dysesthesia syndrome in spinal cord injury patients. Pain 34:109-116.

Blomqvist A, Zhang ET, Craig AD (2000) Cytoarchitectonic and immunohistochemical characterization of a specific pain and temperature relay, the posterior portion of the ventral medial nucleus, in the human thalamus. Brain 123:601-619.

Boivie J (1999) Central pain. In: Textbook of pain (Wall PD, Melzack R, eds), pp 879-914. Edinburgh: Churchill Livingstone.

Boivie J, Leijon G (1991) Clinical findings in patients with central poststroke pain. In: Pain and central nervous system disease (Casey KL, ed), pp 65-75. New York: Raven.

Boivie J, Leijon G, Johansson I (1989) Central post-stroke pain-a study of the mechanisms through analyses of the sensory abnormalities. Pain 37:173-185.

Bowsher D (1996) Central pain: clinical and physiological characteristics. J Neurol Neurosurg Psychiatry 61:62-69.

Bowsher D, Leijon G, Thuomas KA (1998) Central poststroke pain: correlation of MRI with clinical pain characteristics and sensory abnormalities. Neurology 51:1352-1358.

Brown JA, Barbaro NM (2003) Motor cortex stimulation for central and neuropathic pain: current status. Pain 104:431-435.

Bushnell MC, Taylor MB, Duncan GH, Dubner R (1983) Discrimination of innocuous and noxious thermal stimuli applied to the face in human and monkey. Somatosens Res 1:119-129.

Casey KL (1991) Pain and central nervous system disease: a summary and overview. In: Pain and central nervous system disease: the central pain syndromes (Casey KL, ed), pp 1-11. New York: Raven.

Casey KL, Minoshima S, Morrow TJ, Koeppe RA (1996) Comparison of human cerebral activation pattern during cutaneous warmth, heat pain, and deep cold pain. J Neurophysiol 76:571-581.

Cassinari V, Pagni CA (1969) Central pain. A neurosurgical survey. Cambridge, MA: Harvard UP.

Cesaro P, Mann MW, Moretti JL, Defer G, Roualdes B, Nguyen JP, Degos JD (1991) Central pain and thalamic hyperactivity: a single photon emission computerized tomographic study. Pain 47:329-336.

Chmielowska J, Coghill RC, Maisog JM, Carson RE, Herscovitch P, Honda M, Chen R, Hallett M (1998) Positron emission tomography [15O]water studies with short interscan interval for single-subject and group analysis: influence of background subtraction. J Cereb Blood Flow Metab 18:433-443.

Chmielowska J, Coghill RC, Carson RE, Ishii K, chen R, Hallett M, Herscovitch P (1999) Comparison of PET [Oxygen15] water studies with 6 min and 10 min interscan intervals: single subject and group analyses. J Cereb Blood Flow Metab 19:570-582.

Collins DL, Neelin P, Peter TM, Evans AC (1993) Automatic 3D intersubject registration of MR volumetric data in standardized talairach space. J Comput Assist Tomogr 18:192-205.

Craig AD (2000) The functional anatomy of lamina I and its role in poststroke central pain. In: Nervous system plasticity and chronic pain (Sandkühler J, Bromm B, Gebhart GF, eds), pp 137-151. Amsterdam: Elsevier.

Craig AD (2004) Distribution of trigeminothalamic and spinothalamic lamina I terminations in the macaque monkey. J Comp Neurol 477:119-148.

Craig AD, Reiman EM, Evans A, Bushnell MC (1996) Functional imaging of an illusion of pain. Nature 384:258-260.

Davis KD (2000) Studies of pain using functional magnetic resonance im- 
aging. In: Pain imaging (Casey KL, Bushnell MC, eds), pp 195-210. Seattle: IASP.

Davis KD, Kiss ZHT, Tasker RR, Dostrovsky JO (1996) Thalamic stimulation-evoked sensations in chronic pain patients and nonpain (movement disorder) patients. J Neurophysiol 75:1026-1037.

Davis KD, Kwan CL, Crawley AP, Mikulis DJ (1998) Functional MRI study of thalamic and cortical activations evoked by cutaneous heat, cold, and tactile stimuli. J Neurophysiol 80:1533-1546.

Davis KD, Lozano RM, Manduch M, Tasker RR, Kiss ZH, Dostrovsky JO (1999) Thalamic relay site for cold perception in humans. J Neurophysiol 81:1970-1973.

Davis KD, Taub E, Duffner F, Lozano AM, Tasker RR, Houle S, Dostrovsky JO (2000) Activation of the anterior cingulate cortex by thalamic stimulation in patients with chronic pain: a positron emission tomography study. J Neurosurg 92:64-69.

Dougherty PM, Sluka KA, Sorkin LS, Westlund KN, Willis WD (1992) Neural changes in acute arthritis in monkeys. I. Parallel enhancement of responses of spinothalamic tract neurons to mechanical stimulation and excitatory amino acids. Brain Res Rev 17:1-13.

Duncan GH, Bushnell MC, Oliveras JL, Bastrash N, Tremblay N (1993) Thalamic VPM nucleus in the behaving monkey. III. Effects of reversible inactivation by lidocaine on thermal and mechanical discrimination. J Neurophysiol 70:2086-2096.

Erdem A, Yasargil MG, Roth P (1993) Microsurgical anatomy of the hippocampal arteries. J Neurosurg 79:256-265.

Essick GK (1992) Comprehensive clinical evaluation of perioral sensory function. Oral Maxillofac Surg Clin North Am 4:503-526.

Foreman RD, Kenshalo DR, Schmidt RF, Willis WD (1979) Field potentials and excitation of primate spinothalamic neurons in response to volleys in muscle afferents. J Physiol (Lond) 286:197-213.

Forman SD, Cohen JD, Fitzgerald M, Eddy WF, Mintun MA, Noll DC (1995) Improved assessment of significant activation in functional magnetic resonance imaging (fMRI): use of a cluster-size threshold. Magn Reson Med 33:636-647.

Friston KJ, Worsley KJ, Frackowiak RSJ, Mazziotta JC, Evans AC (1994) Assessing the significance of focal activations using their spatial extent. Hum Brain Mapp 1:210-220.

Graziano A, Jones EG (2004) Widespread thalamic terminations of fibers arising in the superficial medullary dorsal horn of monkeys and their relation to calbindin immunoreactivity. J Neurosci 24:248-256.

Greenspan JD, Ohara S, Sarlani E, Lenz FA (2004) Allodynia in patients with post-stroke central pain (CPSP) studied by statistical quantitative sensory testing within individuals. Pain 109:357-366.

Gross RE, Jones EG, Dostrovsky JO, Bergeron C, Lang AE, Lozano AM (2004) Histological analysis of the location of effective thalamic stimulation for tremor. Case report. J Neurosurg 100:547-552.

Hillis AE, Lenz FA, Zirh TA, Dougherty PM, Eckel TS, Jackson K (1998) Hemispatial somatosensory and motor extinction after stereotactic thalamic lesions. Neurocase 4:21-34.

Hirai T, Jones EG (1989) A new parcellation of the human thalamus on the basis of histochemical staining. Brain Res Brain Res Rev 14:1-34.

Hirato M, Watanabe K, Takahashi A, Hayase N, Horikoshi S, Shibasaki T, Ohye C (1994) Pathophysiology of central (thalamic) pain: combined change of sensory thalamus with cerebral cortex around central sulcus. Stereotact Funct Neurosurg 62:300-303.

Jones EG (1985) The thalamus. New York: Plenum.

Jones EG, Friedman DP, Hendry SH (1982) Thalamic basis of place- and modality-specific columns in monkey somatosensory cortex: a correlative anatomical and physiological study. J Neurophysiol 48:545-568.

Katayama Y, Tsubokawa T, Yamamoto T (1994) Chronic motor cortex stimulation for central deafferentation pain: experience with bulbar pain secondary to Wallenberg syndrome. Stereotact Funct Neurosurg 62:295-299.

Kertesz A, Black SE, Tokar G, Benke T, Carr T, Nicholson L (1988) Periventricular and subcortical hyperintensities on magnetic resonance imaging. 'Rims, caps, and unidentified bright objects'. Arch Neurol 45:404-408.

Krayenbuhl H, Yasargil MG (1972) Radiological anatomy and topography of cerebral arteries. In: Handbook of clinical neurology (Vinken PJ, Bruyn GW, eds), pp 65-100. New York: Elsevier.

Lee J, Dougherty PM, Antezana D, Lenz FA (1999) Responses of neurons in the region of human thalamic principal somatic sensory nucleus to me- chanical and thermal stimuli graded into the painful range. J Comp Neurol 410:541-555.

Leijon G, Boivie J, Johansson I (1989) Central post-stroke painneurological symptoms and pain characteristics. Pain 36:13-25.

Lenz FA, Dostrovsky JO, Tasker RR, Yamashiro K, Kwan HC, Murphy JT (1988a) Single-unit analysis of the human ventral thalamic nuclear group: somatosensory responses. J Neurophysiol 59:299-316.

Lenz FA, Dostrovsky JO, Kwan HC, Tasker RR, Yamashiro K, Murphy JT (1988b) Methods for microstimulation and recording of single neurons and evoked potentials in the human central nervous system. J Neurosurg 68:630-634.

Lenz FA, Seike M, Richardson RT, Lin YC, Baker FH, Khoja I, Jaeger CJ, Gracely RH (1993a) Thermal and pain sensations evoked by microstimulation in the area of human ventrocaudal nucleus. J Neurophysiol 70:200-212.

Lenz FA, Seike M, Lin YC, Baker FH, Rowland LH, Gracely RH, Richardson RT (1993b) Neurons in the area of human thalamic nucleus ventralis caudalis respond to painful heat stimuli. Brain Res 623:235-240.

Lenz FA, Kwan HC, Martin R, Tasker R, Richardson RT, Dostrovsky JO (1994) Characteristics of somatotopic organization and spontaneous neuronal activity in the region of the thalamic principal sensory nucleus in patients with spinal cord transection. J Neurophysiol 72:1570-1587.

Lenz FA, Gracely RH, Baker FH, Richardson RT, Dougherty PM (1998) Reorganization of sensory modalities evoked by microstimulation in region of the thalamic principal sensory nucleus in patients with pain due to nervous system injury. J Comp Neurol 399:125-138.

Lenz FA, Ohara S, Gracely RH, Dougherty PM, Patel SH (2004) Pain encoding in the human forebrain: binary and analog exteroceptive channels. J Neurosci 24:6540-6544.

Mehler WR (1962) The anatomy of the so-called "pain tract" in man: an analysis of the course and distribution of the ascending fibers of the fasciculus anterolateralis. In: Basic research in paraplegia (French JD, Porter RW, eds), pp 26-55. Springfield, IL: Thomas.

Mehler WR, Feferman ME, Nauta WHJ (1960) Ascending axon degeneration following anterolateral cordotomy. An experimental study in the monkey. Brain 83:718-750.

Montes C, Magnin M, Maarrawi J, Frot M, Convers P, Mauguiere F, GarciaLarrea L (2005) Thalamic thermo-algesic transmission: ventral posterior (VP) complex versus VMpo in the light of a thalamic infarct with central pain. Pain 113:223-232.

Mountcastle VB (1984) Central nervous mechanisms in mechanoreceptive sensibility. In: Handbook of physiology, Sensory processes (Brookhart JM, Mountcastle VB, Smith ID, Geiger SR, eds), pp 789. Bethesda, MD: American Physiological Society.

Nathan PW, Smith MC (1996) Some tracts of the anterior and lateral columns of the spinal cord. In: Pain (Knighton RS, Dumke PR, eds), pp 47-58. Philadelphia: Lippincott, Williams, and Wilkins.

Nathan PW, Smith MC, Cook AW (1986) Sensory effects in man of lesions of the posterior columns and of some other afferent pathways. Brain 109:1003-1041.

Nguyen JP, Lefaucher JP, Le Guerinel C, Eizenbaum JF, Nakano N, Carpentier A, Brugieres P, Pollin B, Rostaing S, Keravel Y (2000) Motor cortex stimulation in the treatment of central and neuropathic pain. Arch Med Res 31:263-265.

Noordenbos W, Wall PD (1976) Diverse sensory functions with an almost totally divided spinal cord. A case of spinal cord transection with preservation of part of one anterolateral quadrant. Pain 2:185-195.

Nowinski W, Bryan RN, Raghavan R (1996) The electronic clinical brain atlas. New York: Thieme.

Ohara S, Lenz FA (2003) Medial lateral extent of thermal and pain sensations evoked by microstimulation in somatic sensory nuclei of human thalamus. J Neurophysiol 90:2367-2377.

Ohara S, Weiss N, Lenz FA (2004) Microstimulation in the region of the human thalamic principal somatic sensory nucleus evokes sensations like those of mechanical stimulation and movement. J Neurophysiol 91:736-745.

Patel S, Ohara S, Dougherty PM, Gracely RH, Lenz FA (2006) Psychophysical elements of place and modality specificity in the thalamic somatic sensory nucleus (ventral caudal, vc) of awake humans. J Neurophysiol 95:646-659.

Peyron R, Garcia-Larrea L, Gregoire MC, Convers P, Lavenne F, Veyre L, 
Froment JC, Mauguiere F, Michel D, Laurent B (1998) Allodynia after lateral-medullary (Wallenberg) infarct: a PET study. Brain 121:345-356.

Price DD, Bush FM, Long S, Harkins SW (1994) A comparison of pain measurement characteristics of mechanical visual analogue and simple numerical rating scales. Pain 56:217-226.

Rainville P, Bushnell MC, Duncan GH (2000) PET studies of the subjective experience of pain. In: Pain imaging (Casey KL, Bushnell MC, eds), pp 123-156. Seattle: IASP.

Rausell E, Bae CS, Vinuela A, Huntley GW, Jones EG (1992) Calbindin and parvalbumin cells in monkey VPL thalamic nucleus: distribution, laminar cortical projections, and relations to spinothalamic terminations. J Neurosci 12:4088-4111.

Sarlani E, Farooq N, Greenspan JD (2003) Gender and laterality differences in thermosensation throughout the perceptible range. Pain 106:9-18.

Schaltenbrand G, Bailey P (1959) Introduction to stereotaxis with an atlas of the human brain. Stuttgart, Germany: Thieme.

Sherman SM, Guillery RW (2001) Exploring the thalamus and its role in cortical function. New York: Oxford UP.

Soria ED, Fine EJ (1991) Disappearance of thalamic pain after parietal subcortical stroke. Pain 44:285-288.

Steriade M, Jones EG, McCormick DA (1997) Thalamus organisation and function. Amsterdam: Elsevier.
Talairach J, Tournoux P (1988) Co-planar stereotaxic atlas of the human brain. 3D proportional system: an approach to cerebral imaging. Stuttgart, Germany: Georg Thieme Verlag.

Tasker RR, Davis KD, Hutchinson WD, Dostrovsky JO (1997) Subcortical and thalamic mapping in functional neurosurgery. In: Stereotactic and functional neurosurgery (Gildenberg PL, Tasker RR, eds), pp 883-923. New York: McGraw-Hill

Torgerson WS, BenDebba M, Mason KJ (1988) Varieties of pain. In: Proceedings of the 5th World Congress on Pain (Dubner R, Gebhart GF Bond MR, eds), pp 368-374. Amsterdam: Elsevier.

Vestergaard K, Nielsen J, Andersen G, Ingeman-Nielsen M, Arendt-Nielsen L, Jensen TS (1995) Sensory abnormalities in consecutive unselected patients with central post-stroke pain. Pain 61:177-186.

Vogt BA, Sikes RW (2000) The medial pain system, cingulate cortex, and parallel processing of nociceptive information. Prog Brain Res 122:223-235.

White JC, Sweet WH (1969) Pain and the neurosurgeon a forty year experience. Springfield, IL: Charles C Thomas.

Willis WD (1985) The pain system. Basel: Karger.

Willis Jr WD, Zhang X, Honda CN, Giesler Jr GJ (2001) Projections from the marginal zone and deep dorsal horn to the ventrobasal nuclei of the primate thalamus. Pain 92:267-276. 